\title{
Ogilvie Syndrome in a COVID-19 Patient with Pneumonia, Absolute Tachyarrhythmia and Heart Failure: a Case Report
}

\author{
Zoran Matković, ${ }^{1}$ Nataša Đekić Matković ${ }^{1}$
}

\begin{abstract}
The COVID-19 pandemic has recently spread worldwide presenting primarily in form of pneumonia. Gastrointestinal manifestations such as nausea, vomiting, diarrhoea and abdominal pain are less common than respiratory symptoms. However, critically ill patients may develop digestive complications including acute pseudo-obstruction of colon - Ogilvie syndrome. Gastrointestinal symptoms can manifest before the onset of typical respiratory symptoms. Common mucosal immune response underly both-pulmonary and gastrointestinal manifestations (high expression of angiotensin-converting enzyme 2 receptors). This article described a 75-year old female patient who arise Ogilvie syndrome during viral bilateral pneumonia induced by COVID-19. Patient also had an absolute tachyarrhythmia and hearth failure. Diameter of caecum, ascending and transverse colon was 12 to 14 $\mathrm{cm}$. The walls of this segment of large bowel were deserosed, with threatening perforation. Right colectomy was performed. Nine days after the surgery, despite all therapeutic measures taken, there was a fatal outcome due to pulmonary thromboembolisation.
\end{abstract}

Key words: Ogilvie syndrome; COVID-19; Pneumonia; Heart failure; Gastrointestinal manifestations.
(1) General Hospital "Sveti apostol Luka", Doboj, the Republic of Srpska, Bosnia and Herzegovina.

Correspondence: ZORAN MATKOVIĆ

E: 1zona@teol.net M: +387 65740459

\section{ARTICLE INFO}

Received: 3 April 2021 Revision received: 14 May 2021 Accepted: 14 May 2021

\section{Introduction}

The COVID-19 pandemic has recently spread worldwide and became a global challenge to public health. ${ }^{1,2}$ Pneumonia and other respiratory diseases are most common form of COVID-19, but, last months, gastrointestinal (GI) symptoms are recognised as one of the leading extrapulmonary characteristics of the virus. ${ }^{1}$ In regard to the GI system COVID-19 present with nausea, vomiting, diarrhoea and abdominal discomfort and pain. ${ }^{3-8,}$ ${ }^{13} \mathrm{GI}$ symptoms expression are less frequent than pulmonary (about $20 \%$ ) $^{7,8,11}$ but Chinese patients demonstrated that more than half (50.5\%) had at least one of the GI symptom. ${ }^{5}$ Hypomotility-asso- ciated consequences were developed in half of the patients, with $46 \%$ of them developed ileus diagnosed clinically and radiologically. ${ }^{10}$ SARS-CoV-2 virus can be found in faeces. ${ }^{11,12,19}$ Recent studies have reported that GI symptoms can be presented before respiratory manifestation., 5, 8 In cases where nasal swab is negative, faecal testing can be advised in patients with digestive manifestation. ${ }^{9}$ One study suggested that $9 / 76$ cases of positive COVID-19 infection were identified in patient conferred with abdominal pain without respiratory symptoms at the time of COVID-19 pandemic. ${ }^{13}$ COVID-19 patients with GI disease had higher le- 
vels of liver transaminases, prolonged prothrombin time, lower monocyte and lymphocyte counts as well as lower total proteins and albumines. Consequently, they were treated with more antimicrobial medication when compared with patients without GI manifestations. ${ }^{8,14}$

Patients with mild disease severity and critical ill may developed GI complications including bowel ischaemia, bleeding, pancreatitis, Ogilvie syndrome and severe ileus. ${ }^{5,}, 13,15$ In patients with obligatory abdominal surgical treatment, mortality rate is high as $40 \% .{ }^{10}$ We present COVID-19 positive female patient aged 75, who developed acute colonic pseudo-obstruction (Ogilvie syndrome).

\section{Case history}

A 75 years old female patient was admitted in our hospital due to fever, cough, myalgia, anorexia, fatigue and dyspnoea. First symptoms occurred seven days before admission. Peripheral oxygen saturation was $90 \%$ and body temperature was in normal range $\left(36.2^{\circ} \mathrm{C}\right)$. Blood pressure was slightly elevated (150/90 $\mathrm{mmHg})$. Fast Ag test was negative, while PCR test and serologic test (increase IgM antibody) were positive. Blood analysis performed are presented in Table 1. High level of CRP, D-dimer, neutrophilia and lymphopenia were detected. Transaminase levels were in normal range (AST 21, ALT 45). X-ray of chest showed shadows in lower parts of both lungs - Infiltratio basalis bilateralis.

Table 1: Blood-test findings during hospitalisation of the patient

\begin{tabular}{|c|c|c|c|}
\hline Parameter & At admission & $13^{\text {th }}$ day & $20^{\text {th }}$ day \\
\hline $\mathrm{CRP}(\mathrm{mg} / \mathrm{L})$ & 362.51 & 91.25 & 27.25 \\
\hline D-dimer (ng/mL) & $>10000$ & 3600 & - \\
\hline Leukocytes (x 10\%/L (\%)) & 21.47 & 12.01 & 17.01 \\
\hline Neutrophils (x 10\%/L (\%)) & $19.53(91.0 \%)$ & $10.83(90.2 \%)$ & - \\
\hline Lymphocytes (x 10\% /L (\%)) & $0.82(3.8 \%)$ & $0.46(3.8 \%)$ & - \\
\hline NLR & 23.81 & - & - \\
\hline MLR & 1.31 & - & - \\
\hline Monocytes (x 10\%/L (\%)) & $1.08(5 \%)$ & - & - \\
\hline Erythrocytes (cells/mcL) & 4.3 & 3.76 & 4.84 \\
\hline Haemoglobin (g/L) & 136 & 120 & 150 \\
\hline Haematocrit (1/100) & 0.411 & 0.37 & 0.557 \\
\hline Thrombocytes $\left(\times 10^{9} / \mathrm{L}\right)$ & 208 & - & 182 \\
\hline Potassium (mmol/L) & 4.5 & 5.2 & 3.8 \\
\hline Blood urea nitrogen (mg/dL) & 8.9 & - & 10.9 \\
\hline Creatinine ( $\mu \mathrm{mol} / \mathrm{L})$ & 124 & - & 85 \\
\hline LDH (U/L) & 981 & 445 & - \\
\hline
\end{tabular}

NLR: Neutrophile/lymphocyte ratio; MLR: Monocyte/lymphocyte ratio; LDH: Lactate dehydrogenase; CRP: $C$-reactive protein
Antibiotics (Ceftriaxone, $2 \times 2 \mathrm{~g}$ ), low molecular weight heparins (LMWH), crystalloid solutions, vitamin and oxygen therapy was given.

Abdominal discomfort appeared ten days after admission, patient started vomiting. First native abdominal X-ray showed meteorism, without aero-liquids levels, but next two X-rays revealed signs of ileus of large bowel (Figure 1 and 2). After consultative examination by a surgeon conservative treatment was attempted (Bowel rest, NG tube, electrolyte correction, neostigmine). A patient was transferred to surgical department for COVID-19 positive patients.

Later that day, in the evening, on examination, palpation indicated acute abdomen. It was suspected that patient developed mesenteric thrombosis and intestine necrosis due to absolute arrhythmia.

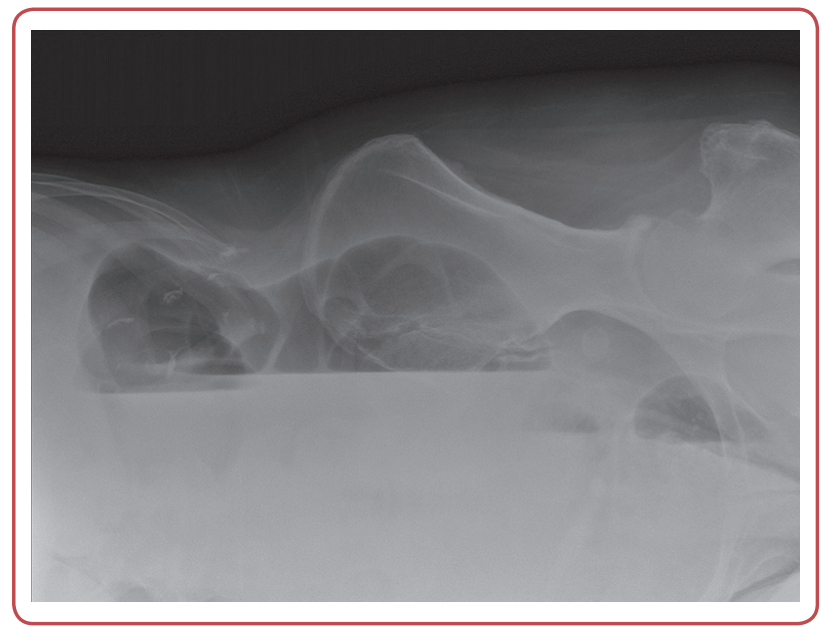

Figure 1: Native X-ray of abdomen (lateral decubitus)

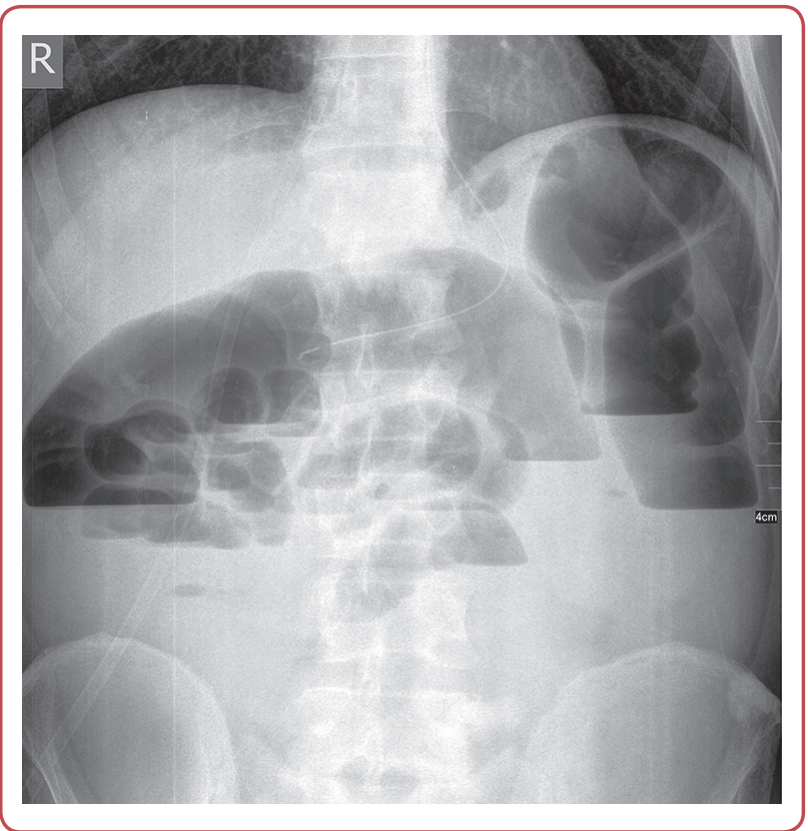

Figure 2: Native X-ray 


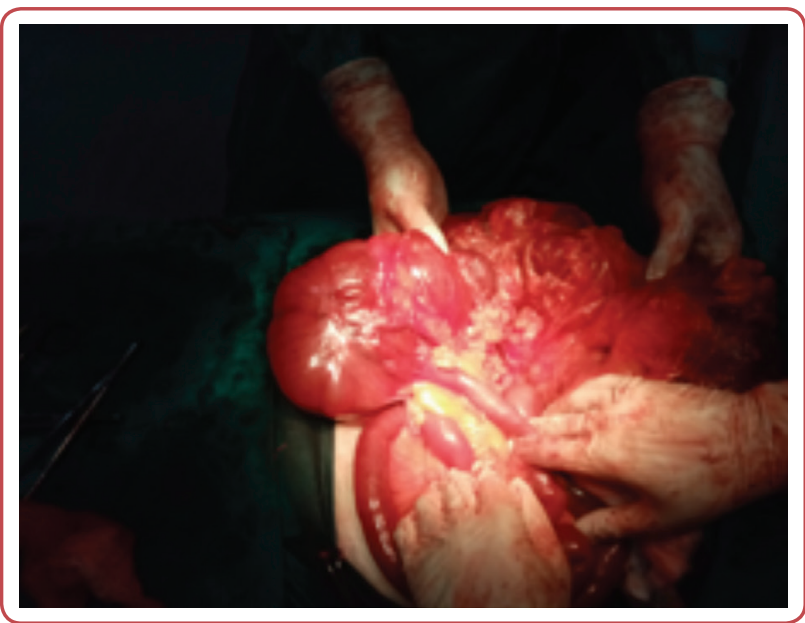

Figure 3: Intraoperative finding: megacolon (caecum, ascendens)

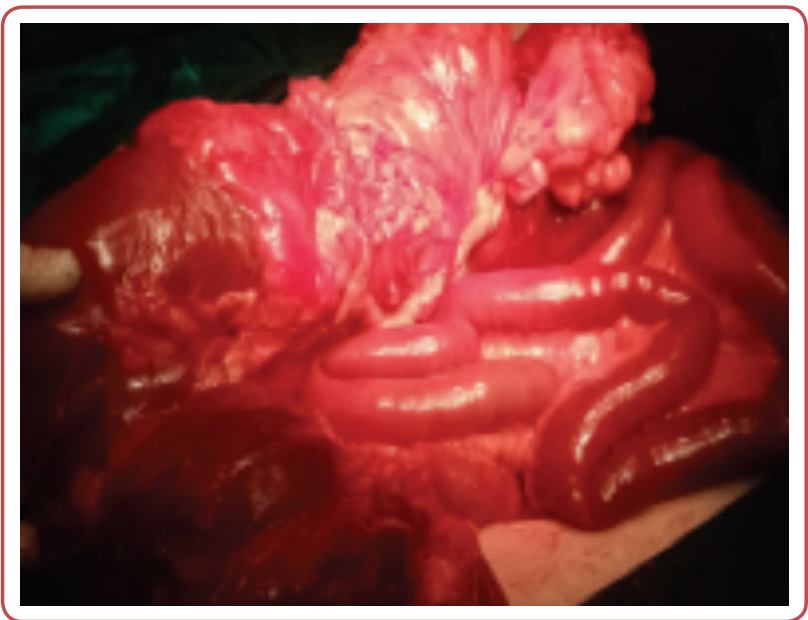

Figure 4: Intraoperative finding: megacolon (caecum, ascendens and transversum)

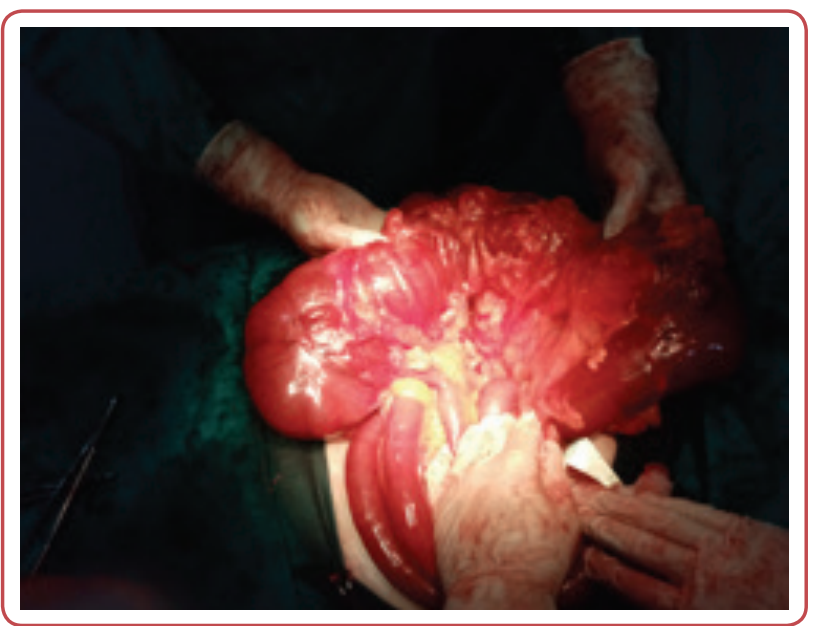

Figure 5: Intraoperative finding: dilated and normal parts of colon

Therefore, an emergency surgery was performed. Intraoperative finding: whole right colon and biggest part of transverse colon $(2 / 3)$ were extremely dilated (megacolon, lumen diameter was between 12-14 cm) (Figure 3-5). Colon segment walls were deserosed, with threatening perforation. Small part of transverse colon and decedent colon were without pathological changes. No mechanical causes of the cessation of the passage was seen It was not possible to suppress content without rupturing of the bowel. It was concluded that was acute pseudo obstruction of large bowel - the Ogilvie syndrome. Extended right hemicolectomy was performed. Nine days after the surgery, despite all therapeutic measures taken, there was a fatal outcome due to pulmonary thromboembolisation.

\section{Pathological findings - macroscopic de- scription}

The colon was with a thinned wall, about $0.1 \mathrm{~cm}$. Lumen was dilated, mucosa was yellow-green, with reduced folds.

\section{Microscopic description}

The intestinal villi were broad and swollen. Mucosa was partially missing and necrotic. The fibrin exudate was seen above mucosa. Transmurally, especially in submucosa, extremely dilated blood and lymph vessels as foci of bleeding and an inflammatory infiltrate dominated by neutrophils. Fibrous-purulent exudate was also present on the serous surface of the colon.

\section{Discussion}

Laboratory and clinical data tracking are essential for increasing treatment success in COVID-19 patients. Laboratory findings are accompanied with severe form of disease. C-reactive protein, D-dimer and NLR have the most important influence on COVID-19 prognosis. ${ }^{8,15}$ GI epithelia with SARS CoV-2 host-cell receptors and high expression of Angiotensin converting enzyme receptor type 2 could explain abdominal organs partaking. ${ }^{16} \mathrm{GI}$ manifestation can be explained with SARS-CoV-2 intestinal tropism. Bowels and glandular epithelial cells of GI can be affected with SARS-CoV-2. Faecal-oral transmission is a potential way of SARS-CoV-2 transmission. ${ }^{17-20}$ Physicians and researchers have conflicted opinions on ACE inhibitors therapy discontinuation due to increasing number and activity of ACE- 2 receptors. ${ }^{21}$

Loss of parasympathetic spinal control of intestine motility can be one of diseases characteristics. Acute colonic pseudo-obstruction (ACPO) syndrome (Ogilvie) is characterised with colon 
distension in absence of mechanical obstruction and it is induced by deteriorated autonomic nervous system. ${ }^{22,23}$ In this case there is not any mechanical barrier in lumen or in wall of colon or extraluminal compression. Colonoscopic decompression is one of effective therapeutic options in patients with this syndrome. Abdominal computed tomography (CT) is the gold standard imaging modality in these cases. ${ }^{24}$ In this case, CT was not performed due to technical issues.

Patients with COVID-19 surgical appearance can have mesenteric inflammation or congestion that can simulate appendicitis or ileus diagnosis. ${ }^{25} \mathrm{Im}$ pact of perioral nutrition is very important in patients with anorexia as leading symptom followed by diarrhoea, nausea and vomiting and abdominal discomfort.

Probiotics are recommended from China National Health commission in treatment of patients with severe form of COVID-19 because they can reduce intestinal disbalance with bacterial displacement and consequently reduce secondary infections. ${ }^{5,8}$

The caloric intake should be more than 15002000 calories, with 75 to $100 \mathrm{~g}$ of protein per day. Oral diet is desirable in patients who are capable to eat. Otherwise, enteral feeding via nasogastric or nasojejunal tube may be useful. This patient had a small oral intake due to loss of appetite. A few studies suggested that the threshold must be reduced for supplemental or full parenteral nutrition as those types of nutrition are not safe or well tolerated. ${ }^{26,27}$

In one study, 58 of 141 patients had digestive hypomotility, although these GI complications could be associated with metabolic and electrolyte disturbances or pharmacologic adverse events, experienced in patients with severe form of disease. Severe acute respiratory syndrome initiated by thrombosis small vessel or viral enteropathy requires further investigation. ${ }^{10,28}$

Histopathological specimen of resected bowel shows COVID-19 initiated microthrombosis, inflammatory infiltrate and necrotic fields leading to GI perforation. ${ }^{1,10,28}$ In case of the presented patient similar findings were registered.

Doctors treating COVID-19 patients should be attentive of these consequences and be watchful in cases where gastrointestinal symptoms required surgical consultation. In critically ill patients there is high frequency of GI complications, due to intestinal ischaemia group of patients can required urgent surgery.

\section{Conclusion}

Early recognition and management of GI complications in COVID-19 patients, primarily conservative, are extremely important to reduce rates of mortality. As evidence for GI involvement increase, a suspicion for COVID-19 infection must be managed in all cases of patients with abdominal discomfort requiring surgical consultation. Ogilvie syndrome is one of possible GI manifestations, and one must think about this because delayed diagnosis often can lead to poor disease course and fatal outcome.

\section{Acknowledgements}

None.

\section{Conflict of interest}

None.

\section{References}

1. Ibrahim YS, Karuppasamy G, Parambil JV, Alsoub H, AlShokri SD. Case report: paralytic ileus: a potential extrapulmonary manifestation of severe COVID-19. Am J Trop Med Hyg 2020 Oct;103(4):1600-3.

2. Tse F, Borgaonkar M, Leontiadis GI. COVID-19: Advice from the Canadian Association of Gastroenterology for Endoscopy Facilities, as of March 16, 2020. J Can Assoc Gastroenterol 2020 Jun;3(3):147-9.

3. Wang D, Hu B, Hu C, Zhu F, Liu X, Zhang J, et al. Clinical characteristics of 138 hospitalized patients with 2019 novel coronavirus-infected pneumonia in Wuhan, China. JAMA 2020 Mar 17;323(11):1061-9.

4. Azwar MK, Kirana F, Kurniawan A, Handayani S, Setiati S. Gastrointestinal presentation in COVID-19 in Indonesia: A case report. Acta Med Indones 2020 Jan;52(1):63-7.

5. Pan L, Mu M, Yang P, Sun Y, Wang R, Yan J, et al. Clinical characteristics of Covid patients with digestive symp- 
toms in Hubei, China: A descriptictive, cross-sectional multicentric study. Am J Gastroenterol 2020;115(5):76673.

6. Nobel YR, Phipps M, Zucker J, Lebwohl B, Wang TC, Sobieszczyk ME, et al. Gastrointestinal symptoms and coronavirus disease 2019: A case control study from United States. Gastroenterology 2020;59(1):373-5.

7. Ramachadran P, Onukogu I, Ghantas S, Gajedran M, Perisetti A, Goyal H, et al. Gastrointestinal symptoms and outcomes in hospitalized Corona virus disease 2019 patients. Dig Dis 2020;38:373-9.

8. Mao R, Qiu Y, He JS, Tan JY, Li XH, Liang J, et al. Manifestations and prognosis of gastrointestinal and liver involvement in patients with COVID-19: a systematic review and meta-analysis. Lancet Gastroenterol Hepatol 2020 Jul;5(7):667-78.

9. Wu Y, Guo C, Tang L, Hong Z, Zhou J, Dong X, et al. Prolonged presence of SARS-CoV-2 viral RNA in faecal samples. Lancet Gastroenterol Hepatol 2020 May;5(5):434-5.

10. Kaafarani HMA, El Moheb M, Hwabejire JO, Naar L, Christensen MA, Breen K, et al. Gastrointestinal complications in critical ill patients with COVID-19. Ann Surg 2020 Aug;272(2):e61-e62.

11. Sattar Y, Connerney M, Rauf H, Saini M, Ullah W, Mamtani S, et al. Three cases of COVID-19 disease with colonic manifestations. Am J Gastroenterol 2020 Jun;115(6):948-50.

12. Han C, Duan C, Zhang S, Spiegel B, Shi H, Wang W, et al. Digestive symptoms in COVID-19 patients with mild disease severity: clinical presentation, stool viral RNA testing, and outcomes. Am J Gastroenterol 2020 Jun;115(6):91623.

13. Tian Y, Rong L, Nian W, He Y. Review article: gastrointestinal features in COVID-19 and the possibility of faecal transmission. Aliment Pharmacol Ther 2020 May;51(9):843-51.

14. Saeed U, Sellevoll HB, Young VS, Sandbaek G, Glomsaker T, Mala T. Covid-19 may present with acute abdominal pain. Br J Surg 2020 Jun;107(7):e186-e187.

15. Bastug A, Bodur H, Erdogan S, Gokcinar D, Kazancioglu S, Kosovali BD, et al. Clinical and laboratory features of COVID-19: Predictors of severe prognosis. Int Immunopharmacol 2020 Nov;88:106950. doi: 10.1016/j.intimp.2020.106950.

16. Bourgonje AR, Abdulle AE, Timens W, Hillebrands JL, Navis GJ, Gordijn SJ, et al. Angiotensin-converting enzyme 2 (ACE2), SARS-CoV-2 and the pathophysiology of coronavirus disease 2019 (COVID-19). J Pathol 2020 Jul;251(3):228-48.
17. Zhang H, Li HB, Lyu JR, Lei XM, Li W, Wu G, et al. Specific ACE2 expression in small intestinal enterocytes may cause gastrointestinal symptoms and injury after 2019nCoV infection. Int J Infect Dis 2020 Jul;96:19-24.

18. Xiao F, Tang M, Zheng X, Liu Y, Li X, Shan H. Evidence for gastrointestinal infection of SARS-CoV-2. Gastroenterology 2020 May;158(6):1831-3.e3.

19. Chen Y, Chen L, Deng Q, Zhang G, Wu K, Ni L, et al. The presence of SARS-CoV-2 RNA in the feces of COVID-19 patients. J Med Virol 2020 Jul;92(7):833-40.

20. Zhang H, Kang Z, Gong H, Xu D, Wang J, Li Z, et al. The digestive system is a potential route of 2019-nCov infection: a bioinformatics analysis based on single-cell transcriptomes. bioRxiv 2020; 01.30.927806doi:10.1101/2020.01. 30.927806.

21. Igic R. Pharmacologists view of the new corona virus. Scr Med 2020;51(1):6-8.

22. Khan Z, Mukhtar K, Roman G, Aun R, Hassan, Ahmed M, et al. Ogilvie syndroma in a patient with Covid-19 infection. Am J Gastroenterol 2020;115:862-3.

23. Wells CI, O'Grady G, Bissett IP. Acute colonic pseudo-obstruction: A systematic review of aetiology and mechanisms. World J Gastroenterol 2017 Aug 14;23(30):563444.

24. Bhayana R, Som A, Li MD, Carey DE, Anderson MA, Blake MA, et al. Abdominal imaging findings in COVID-19: preliminary observations. Radiology 2020 Oct;297(1):E207-E215.

25. Ashcroft J, Hudson VE, Davies RJ. COVID-19 gastrointestinal symptoms mimicking surgical presentations. Ann Med Surg (Lond) 2020 Jun 24;56:108-9.

26. Martindale A, Patel JJ, Taylor B, Warren M, Mc Glove SA. American Society for parenteral and enteral nutrition(ASPEN). Nutrition therapy in the patients with COVID-19 disease requiring ICU care. [Cited 1-May-2021] Available at: https://www.nutritioncare.org/uploadedFiles/Documents/Guidelines_and_Clinical_Resources/ Nutrition\%20Therapy\%20COVID-19_SCCM-ASPEN.pdf.

27. Aguila EJT, Cua IHY, Fontanilla JAC, Yabut VLM, Causing MFP. Gastrointestinal manifestations of COVID-19: Impact on nutrition practices. Nutr Clin Pract 2020 Oct;35(5):800-5.

28. Connors JM, Levy JH. Thromboinflammation and the hypercoagulability of COVID-19. J Thromb Haemost 2020 Jul;18(7):1559-61. 